\title{
Analysis of the Current Development of Lacquer Painting Art
}

\author{
Tao Xu \\ School of Arts, East China University of Technology, Nachang, Jiangxi Province, 344000
}

\section{Keywords: Lacquer Paint Art; Aesthetics; Development Problems}

\begin{abstract}
Lacquer painting is a new type of painting. The development of lacquer painting art in the current era is also based on rules and must be studied in the experience and interpretation of Chinese and Western art. There are also many problems that need to be solved in its development. Only by adhering to the multiple development road, can the lacquer painting art be based on the new forms of ethnic painting and achieve innovation.
\end{abstract}

\section{Introduction}

The ancient Chinese lacquer art has a long history. The Hemudu culture of the lacquer wood bowl proves that the history of people using paint is far longer than the history of Chinese characters. Although there was no lacquer painting in the painting in ancient times, it was still attached to lacquer ware, but the craftsmanship of using paint was already very mature. The independent rise of Chinese lacquer painting was in the second half of the $20^{\text {th }}$ century. On the one hand, it was affected by the culture of Chinese traditional lacquer art for thousands of years; on the other hand, it was inspired by foreign painting forms and ideas. As lacquer master Qiao Shiguang said: "It is Vietnam that pioneered the lacquer painting. The independence of Chinese lacquer paintings was inspired by the lacquer paintings of Vietnam and inspired by the concept of modern art in the creative work of contemporary Chinese lacquer painters. " $[1]$

\section{Current Development of Lacquer Painting}

In the first half of the $20^{\text {th }}$ century, influenced by the background of the times, people's understanding of lacquer was limited to ancient life and decorative articles. There is no separation from the three-dimensional modeling to the two only plane lacquer paintings. The production of lacquer ware is limited to workshops and teachers and such a model in which teachers teach the students. Coupled with the domestic political environment, people can't see the most precious essence of Chinese tradition from the dream of accepting new Western ideas. The Chinese people have taken a fresh look at new ideas and concepts from abroad and accepted new knowledge to change the status of the old society. There is nothing wrong with this in mind, but the cultural concept has entered such an extreme as "respecting foreign affairs". His metaphysical thinking denies too much to China's traditional culture and his eyes only look outward, and his words must include Greece. Regardless of both theory and practice, they ignore and reject the expressive literature and art that has a history of several thousand years in China and a deep tradition. In addition, from the feudal society to the opening of the country, traditional handicrafts are facing difficult challenges. This historical environment is bound to limit the development of China's lacquer arts. The number of lacquer painting creators is less than that of Chinese paintings and oil paintings. The lacquer painting arts are also relatively simple in form.

The early days of the development of lacquer paintings were shortly after the founding of the new China. It was born out of lacquer ware, influenced by lacquer ware production process, favored craftsmanship and production, and focused on decorative effects. At that time, lacquer artists such as Shen Fuwen and Qiao Shiguang and other older lacquer masters were rooted in the traditional lacquer culture. The drew lessons from the experience of absorbing Vietnamese lacquer paintings, used lacquer ware techniques in two-dimensional plane space, which was their most important contributions. As the style of the ancient lacquer ware is more decorative and the craftsmanship is very demanding, and this craftsmanship is somewhat mysterious, the work of digging and 
discovering the traditional paintwork itself is also huge. Therefore, the change from lacquer ware to painting will focus more on the craftsmanship of the work.

The social background at that time had a certain influence on the artistic research of lacquer works. This is also the reason why the lacquer works cannot be artistically explored during this period. We know that the centuries-old history of the 20th century is rugged and bumpy in terms of artistic conception. In terms of the concept of art, Western classicism has a profound impact on our artistic concept. In such a social context, it was very difficult to develop the lacquer art. Therefore, during this period, lacquer painting works have a lot of research on lacquer painting materials and techniques, and there is a lack of a good environment and space for artistic exploration. There are fewer people who study lacquer painting in depth, and the art forms of the works are relatively simple. It is at the experimental stage of exquisite craftsmanship. The social form emphasized that works of art should reflect the theory of national independence, social reflection, and social service. The art and craftsmanship of lacquer painting art has not yet been solved. Therefore, in the early years after the founding of the new China, lacquer painting works, performance techniques, and more social topics were reflected. The aesthetic theory in the early years after the founding of the People's Republic of China emphasized individuality and emphasized that the sentimental aspects of human emotions, feelings, imaginations, intuitions, etc., were not given adequate attention. Art works reflect social life and become a feature of this period. The relationship between aesthetics and morality is also the fundamental issue of socialist aesthetics. Therefore, although there are a certain number of lacquer paintings in this period, the forms are relatively single. The study of traditional lacquer techniques is higher than the analysis of theories. The art of lacquer painting involves too much technicity. It does not begin with the essence of art and explores the fundamental issues of artistic effect. In addition, because lacquer painting is a new type of painting, there are few people who study lacquer art theory, and there is a tendency to have a great unification in the form of works. Lacquer paintings are less influenced by other paintings, such as oil painting and Chinese painting theory. ${ }^{[2]}$

In the 1950s and 1960s, a series of works that reflected the struggle for national independence and unity and people's lives appeared in Vietnam. Gradually, Vietnamese lacquer paintings were introduced into the field of modern painting. The lacquer masters of the old generation worked hard to learn traditional lacquer techniques and laid the foundation for the development of modern Chinese lacquer painting. In 1964, there were lacquer paintings that participated in the National Art Exhibition, and by the 1984 Sixth National Art Exhibition, lacquer paintings had begun to take shape. Lacquer paintings were further confirmed as an independent painting species. The new form of Chinese national painting - lacquer painting has gained recognition from society. ${ }^{[3]}$ After the art thought in 1985, a group of lacquer painting artists returned to the tradition and hoped for the reconstruction of history by postmodernism. Lacquer painting is no longer the appendage of lacquer ware but has become an independent aesthetic object.

By the 1984 Sixth National Art Exhibition, lacquer paintings had gradually grown in size and were further confirmed as an independent painting species, and several works were awarded. This exhibition has great significance. On the one hand, it affirms the lacquer painting art and proves the unique aesthetic value of lacquer painting art. On the one hand, it is also an examination of the overall level of the development of lacquer painting since the reform and opening up in 1978. After the opening of artistic concepts, the forms of lacquer paintings are novel and varied, and artistic languages are more abundant. The artistic expression does not deviate from life itself, but it also has a strong sense of form. At the subsequent $7^{\text {th }}$ National Art Exhibition, many outstanding lacquer paintings appeared. Their common feature is to maintain the beauty of the lacquer painting process, and to reflect the artist's works on life. Some works express abstraction and composition, and some work pursue artistic conception. ${ }^{[4]}$

From 1984 to 2000, compared with the previous period, the art of lacquer painting has been strengthened with respect to craftsmanship, and craftsmanship that is consistent with the painting language has been raised to a new height. For example, painting, grinding, changing and other techniques; material use is relatively mature; lacquer technology has also been developed. There are 
also many traditional techniques that are still far from the lacquer painting. The lacquer painting technique has been improved, and the types of techniques and skills are abundant. At this time, the lacquer painting works gave people a lot of inspiration in terms of artistry. After the 1985 artistic trends, the art community sought to find new blood from Western modern art. It brought new vitality to the Chinese art world. However, lacquer painting did not follow the curved path of localization of oil painting. Because lacquer art itself has a long history of relationship with tradition. Judging from the representative lacquer paintings of this period, it is either affirming excellent traditional Chinese culture, absorbing nutrients from traditional cultures, and highlighting the uniqueness of lacquer painting. They are either rebelling or reconstructing traditions, re-interpreting traditional cultures, and setting a new path. They either absorb Western aesthetic ideas and emphasize modernity. Regardless of the formal style, they have their merits.

The first national lacquer painting exhibition in 2002 was of epoch-making significance in the history of lacquer painting. The lacquer painting works were relatively rich in forms, subjects, and contents. Some award-winning works, such as Professor Chen Jinhua's "Big Year", reaching a new height in craft production. On the one hand, they are technologically advanced, and on the other hand, they have expanded their lacquer painting techniques and methods. They also show profound skills in artistic expression. ${ }^{[5]}$ They have both traditional colors and traditional customs, without losing the sense of modernity and the times. The perfect combination of craftsmanship and artistry. The first lacquer exhibition marks the basic maturity of the lacquer painting art. They are an affirmation of the combination of lacquer painting and art. Of course, judging from the overall lacquer painting works, the artistry is more similar to the decorative painting, Chinese painting, and oil painting. The language of paint itself is not enough.

The second national lacquer painting exhibition in 2007 was the largest feast in the history of lacquer painting. Many new works emerged. The work is of a novel style and craftsmanship. Some of the work techniques themselves have reached a certain height. For example, Heilongjiang Zhang Zeguo's egg shells show the theme of lacquer paintings in the form of snow, the characters of the south and the embossing of traditional characters. There are also works with relative personalities that weaken the lacquer painting process, so that it does not push light, does not polish directly the artistic effects and is also very exciting. For the purpose of the effect of screen art, it is a new interpretation of lacquer painting as "painting". The exhibition has a diversified perspective both in terms of craftsmanship and artistry. The lacquer painting art is moving toward a diversified development situation. This diversification includes different artistic concepts, style schools, and forms and methods. They also coexist, influence and lead the game. Many lacquer artists are making arduous efforts and are constantly promoting the artistic appeal of lacquer painting works. They advocate the diversified development of the lacquer painting art form in order to get rid of many problems in the current lacquer painting art. ${ }^{[6]}$

In modern times, the lacquer painting art is moving toward a pluralistic situation. This diversity encompasses different artistic concepts, style schools, and forms and methods. They simultaneously coexist and influence each other. If we say that the development of other forms of art in China is accompanied by Western modernism and postmodernism in the wave of criticism in China, it has gradually grown and developed in a contradiction between the denial and affirmation of history and culture. Therefore, the art of lacquer painting originated from traditional arts and crafts and did not really accept the criticism of pure art theory. To develop the lacquer painting art, the problem left behind is to establish and improve the aesthetic theory of lacquer painting; on the other hand, it is necessary to regain the tradition.

\section{Problems in the Current Development of Lacquer Painting}

Today, lacquer paintings are increasingly exhibited at the national level as independent paintings. For example, every five-year national exhibition of lacquer art, national youth art exhibitions, national lacquer art exhibitions, Xiamen lacquer biennials, various types of lacquer painting exhibitions of private organizations, and personal exhibitions are various. There have been many excellent works, unprecedented development in the level and scale, and rapid development of the 
lacquer painting art, with gratifying results. If it is to develop a good development trend of lacquer painting, the author thinks it is necessary to solve some contemporary problems.

First of all, when a pure artwork is given strong craftsmanship performance, it often creates contradictions between its artistic and craftsmanship. How to solve this contradiction will naturally become an important topic for art theory researchers. This is the case with lacquer painting works of art. As a new and independent type of painting, the relationship between artistry and craftsmanship has a different focus in the lacquer art creators. Simply emphasizing the artistry, it is easy to lose the uniqueness and craftsmanship of the lacquer art; however, simply emphasizing the craftsmanship of the work will make the lacquer art work mundane and lose its artistic appeal as a pure art work. Therefore, in the current lacquer painting artistic circle, the two will be emphasized at the same time. The contradiction between the artistry and craftsmanship of lacquer painting is a subject that needs long-term research. Compared with other kinds of paintings such as oil paintings and traditional Chinese paintings, the lacquer paintings are very crafty and it is precisely this that has increased the difficulty of lacquer painting. However, in the case of a good solution, it will also enhance the artistry of the work. How to realize the artistic appeal of the works through technological techniques has yet to be continuously studied by numerous lacquer artists. At present, the use of Western aesthetics and traditional Chinese aesthetic theories to study this issue is still of advanced significance. However, there are not many theoretical articles that can be explored in depth. I hope there will be more enthusiasm for researchers who are interested in lacquer art theory.

Second, China's traditional lacquer art, coupled with the expression of Vietnam's lacquer painting art, does not equal Chinese lacquer painting. How to strengthen the nationalization of the lacquer painting art concept is our contemporary issue of "revitalizing traditional culture". The art of lacquer painting is our tradition, but the concept is influenced by Western aesthetic theory. The lacquer paintings that were created in full accordance with Western ideas using the skills of their own tools were not Chinese lacquer paintings. It is true that only the lacquer paintings created using the concepts of the fine arts and cultures of our own national tradition are lacquer paintings with the characteristics of the nation. Must have a national, modern, open art form in order to stand in the world of art. How to absorb the excellent culture of the nation and implement the essence of national culture in specific practices remains an arduous task. Therefore, at present, the literary and art theory circles emphasize diversified development and try to come out of the new world through the theme of diversified development. This is an active development of art theory. With diversified development, the Eastern and Western cultures will be eclectic, and more extensive creative ideas will emerge, such as free form, open concept, and rich themes. After the precipitation of time, China's lacquer painting art was repositioned from numerous artistic styles. In short, multiple developments are historically inevitable. It is the only way after the open concept of lacquer painting. Regardless of how the Chinese and western theories are absorbed and learned, there is a problem of strength and perspective. At present, there are not many works that can demonstrate profoundness and brilliance. It is necessary for lacquer painters to improve their technological knowledge and improve their own knowledge and culture. A person who can understand the traditional culture of a nation can create a quality product. A person who understands the theory of modern Western aesthetics can create works with a sense of the times.

Third, it is necessary to strengthen and deepen the study of the lacquer art theory. The lacquer painting art is different from other easel paintings and has its own uniqueness. There are commonness and personality in the aesthetic theory and other art forms. Therefore, it is of great value and significance to regard the lacquer art theory as the object of independent study. The number of lacquer painting related papers published in various journals has gradually increased. With the active exhibition, the new national lacquer arts committee attaches importance to the study of lacquer art theory (such as the addition of a special lacquer painting). Theoretical research is like bamboo shoots springing up. 


\section{Conclusion - Some Feasible Ways of Lacquer Painting Creation at Present}

First, starting from the long-established cultural traditions, aesthetic traditions, and ideological traditions of the Chinese nation, a theoretical study of this kind of paintings was conducted to form a traditional aesthetic theory that emphasizes the characteristics of the nation. In the contemporary culture that focuses on regaining the tradition, it will gradually carry out meaningful practices and attempts in the direction of the quality and humanistic spirit of the work. Humanism refers to various cultural phenomena of human society. Including the meaning of human existence, human dignity, value, morality, knowledge, sentiment, meaning and other personality connotation, with all kinds of human cultural culture. The humanistic spirit refers to a high degree of thought that attaches great importance to the values of people and people. It pays attention to the significance of human existence and people's dignity, value, moral concepts and cultural traditions, and the harmony between humans and society and nature. Good lacquer artwork is definitely not a simple process of craftsmanship. It must embody human ideals, aspirations, emotions, will, values, morality, dignity, personality, artistic accomplishment, and living conditions. It can absorb nutrition from different historical cultures and different countries. Writing is for conveying truth, which is a basic requirement for ancient Chinese writing on the article. For the so-called "Tao" of the ancients, its numerous ideas on self-cultivation and reliance are still inspiration and reference for today. "Containing Taoism" in contemporary artistic creation emphasizes the promotion of humanistic spirit.

Second, use the various aesthetic theories of Western relative systems to sort out the theoretical knowledge of Chinese lacquer painting, forming an aesthetic theory that emphasizes modernity. The lacquer painting art must face the deepening of the contemporary knowledge structure, and philosophical aesthetics repositions the aesthetic value judgment, meaning, category, and other challenges. For example, L. Wittgenstein's analytical aesthetics believes that the concise answer to what beauty is: the United States is a lot of different things, but when it is not well understood, the term 'beauty' is used on them." The ambiguity, crypticity, and ambiguity of words used in aesthetic analysis impact traditional aesthetics. And it is causing the transformation of traditional aesthetics to anthropological ontology aesthetics. The famous philosopher Mr. Li Zehou affirmed the value of an ontology aesthetics of anthropology and pointed out the diversification of aesthetics: "The theory is a whole that is composed of many aspects. Therefore, we can approach it from different perspectives, different approaches, different issues, and different requirements..." In addition, psychoanalytic unconsciousness theory, Gestalt psychology perception theory, new criticism and structuralism on the objective analysis of works of art ... and so on are all theoretical knowledge that can be introduced into the lacquer painting art.

Third, it does not exclude the exchange and integration of Eastern and Western cultures, advocates the absorption of advanced ideas of various cultures, and forms an aesthetic theory that emphasizes openness. No matter which concept, as long as it is conducive to the development of the lacquer painting industry in China, it is good. The diversified development theme emphasizes the nationality, modernity, and openness of artistic works. However, there are many problems in these three aspects. Starting from national traditions, which are excellent cultures and which are dross, they should be carefully analyzed. Absorbing tradition does not add a few ancient symbols or symbols to the picture. It is necessary to dig deeper into the traditional essence and humanistic connotation from the point of view. The works have the thickness of culture. Absorbing too much Western culture will inevitably run counter to the localization of lacquer painting. What are the scales and limits of the exchange and integration of Eastern and Western cultures? Absorption and integration in culture is not that alcohol can produce good liquor. What kind of perspective should be taken into the window of the theoretical study of lacquer painting? It is a subject of sustainable research. The author believes that the outstanding traditional culture and aesthetic theory of the nation should occupy a dominant position. This point cannot be lost, nor can it be replaced by Western cultural intervention. Based on traditions, absorbing foreign cultures, and absorbing and digesting themselves, we have formed the theoretical knowledge with nationalization, time significance, and modernity, which is of contemporary significance. 
In summary, the lacquer painting art has been difficult to develop and there are many artists who have worked hard for it. It is not easy! The problem of lacquer painting itself involves ethnic, social, and time issues as well as specific issues of theory and practice. This requires the hard work of many artists! I believe that in the future China's lacquer painting art will surely climb the peak!

\section{References}

[1] Shiguang Qiao, Painting Techniques and Artistic Expression, Hunan Fine Arts Publishing House, 1996.8

[2] Xin Ru, Fanren Zeng, Chinese Aesthetic Yearbook 2005, Henan People's Publishing House, 2007.9

[3] Liyuan Zhu, an Overview of Western Aesthetic Masterpieces, Jiangxi People's Publishing House, 2000.10

[4] Li Huawei. Changes of Public Space in Rural Areas and Construction of People's Life Order: A Case Study of the Interaction between Clans, Temple Fair, and Rural Christianity in Lixi, Western Henan Province . Folklore Studies, 2015.10

[5] Chen Jinquan et al. The Sociological Significance and Planning Design of Rural Public Space . Journal of Jiangxi University of Science and Technology, 2013, 2

[6] Lin Xuechun. A Review of the Study of Village Governance Models since the Self-government of Contemporary Chinese Villagers Agricultural Economics Guide, 2015.5

\section{Introduction to the author:}

Xu Tao, male, born in Shangzhi, Heilongiiang Province on February 22, 1976, Han nationality, post graduate, Associate Professor, now works at Art Design Department of School of Art, East China Institute of Technology, Jiangxi Province. His main research direction is lacquer painting creation and research.

Correspondence address: No. 892, Fenglin Avenue, Economic Development Zone, Nanchang City, Jiangxi Province, China. Fenglin Campus of East China Institute of Technology.

Telephone: 15907041066 (mobile phone) $\quad$ Postcode: 330000 